\title{
An old disease re-emerging: acute rheumatic fever
}

\author{
Authors: Asim Khan, ${ }^{A}$ Nurhan Sutcliffe ${ }^{B}$ and Ali SM Jawad ${ }^{C}$
}

We present the case of a 41-year-old Australian woman with a 3-day history of fevers and migratory polyarthritis. Three weeks prior she had been treated by her GP with phenoxymethylpenicillin for acute tonsillitis. Examination confirmed synovitis. Systemic assessment including cardiovascular, neurological and skin examination was unremarkable.

Abnormal investigations included a leucocytosis with neutrophilia, C-reactive peptide of $116 \mathrm{mg} / \mathrm{L}$, erythrocyte sedimentation rate of $103 \mathrm{~mm} / \mathrm{hour}$ and acute transaminitis. The antistreptolysin 0 titre was $304 \mathrm{IU}$, which increased to 1,250 IU after 2 weeks. Troponin T, electrocardiogram and echocardiography were all normal. The patient was treated for acute rheumatic fever with corticosteroids and a 10-day course of cephalexin.

After 8 weeks, she made a full recovery and had normalised inflammatory markers and liver biochemistry. She was then commenced on monthly prophylactic intramuscular benzathine penicillin. This case study aims to raise awareness of the presentation, diagnosis and management of acute rheumatic fever.

KEYWORDS: Acute rheumatic fever, migratory polyarthritis

\section{Case report}

A 41-year-old Australian woman presented to the emergency department with a 3-day history of migratory polyarthritis and fevers. Three weeks earlier, she had been treated for acute tonsillitis with 5 days of phenoxymethylpenicillin $250 \mathrm{mg}$ qds.

Her left elbow was the first affected joint, but after 24 hours she developed arthritis of the left wrist and ankle, and of both knees. The following day, she developed right wrist and ankle arthritis although the other affected joints were improving with complete recovery of the left elbow. She had tried naproxen with modest improvement. There were no other constitutional symptoms, nor were there stigmata of infection, spondyloarthropathy, connective tissue disease or vasculitis. The patient had neither travelled nor

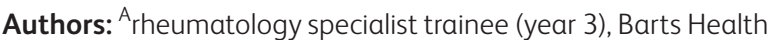
NHS Foundation Trust, London, UK; ${ }^{B}$ consultant rheumatologist, Barts Health NHS Foundation Trust, London, UK; ' ${ }^{\text {Consultant and }}$ professor in rheumatology, Barts Health NHS Foundation Trust, London, UK had contact with animals recently. She had no comorbidities and did not take regular medication. She was a non-smoker, drank little alcohol and did not use illicit drugs.

Apart from a fever $\left(38.2^{\circ} \mathrm{C}\right)$, her other vital observations were normal. Musculoskeletal examination demonstrated an antalgic gait and synovitis in the ankles, wrists and knees. Systemic examination, including examination of the cardiovascular and neurological systems, was unremarkable. Furthermore, no rash, lymphadenopathy or pharyngitis was evident.

\section{Diagnosis}

Blood tests revealed neutrophilia $\left(13.3 \times 10^{9}\right.$ neutrophils/L), a C-reactive peptide (CRP) of $106 \mathrm{mg} / \mathrm{L}$ and an erythrocyte sedimentation rate (ESR) of $38 \mathrm{~mm} /$ hour. Urinalysis and other blood tests, including liver function, were normal. Ankle and knee radiographs demonstrated small effusions that were not amenable to blind aspiration.

The patient was diagnosed with reactive arthritis; differentials included acute rheumatic fever, viral polyarthritis, adult-onset Still's disease or a new presentation of chronic inflammatory arthritis.

Polyarticular septic arthritis was clinically excluded on the basis that the patient was well systemically, having a full range of movement in all affected joints, and because of a lack of risk factors for polyarticular septic arthritis. We therefore did not aspirate her joints.

\section{Initial management}

The patient was commenced on a weaning regimen of $20 \mathrm{mg}$ prednisolone. An antistreptolysin O (ASO) titre and screening for inflammatory arthritis and viruses were arranged.

\section{Case progression}

Two days later, the polyarthritis had improved but intermittent fevers continued. The patient also described two episodes of palpitations and dyspnoea. Systemic examination was again unremarkable.

Investigations revealed an ASO titre of 304 IU, ongoing neutrophilia (21.5 $\times 10^{9}$ neutrophils/L), and elevated CRP (116 mg/L) and ESR (88 mm/hour). The patient also developed deranged liver biochemistry (alanine aminotransferase [ALT] 406 IU/L, alkaline phosphatase [ALP] 186 IU/L); a subsequent liver screen including an abdomen ultrasound was unremarkable. Cardiac enzymes, electrocardiogram (ECG) and a transthoracic echocardiogram were all normal. An autoimmune screen for inflammatory arthritis, connective tissue disease and vasculitis 
was negative. Similarly, a virology screen for HIV, Epstein-Barr virus (EBV), cytomegalovirus (CMV), hepatitis B virus (HBV) and hepatitis $C$ virus (HCV) was unremarkable.

In light of this presentation and these investigation findings, this patient fulfilled the 2015 Jones criteria and was diagnosed with acute rheumatic fever (ARF). We commenced cephalexin $500 \mathrm{mg}$ qds for 10 days to eradicate group A streptococcus.

Five days later, the patient had ongoing fevers and right ankle monoarthritis. Her inflammatory markers and liver biochemistry remained static but stable. Her prednisolone dose was subsequently increased to $40 \mathrm{mg}$. After 2 weeks, there was resolution of symptoms. A repeat ASO titre was 1,300 IU, indicative of the convalescence phase. Both ESR and CRP had fallen to $25 \mathrm{~mm} /$ hour and $20 \mathrm{mg} / \mathrm{L}$, respectively, with correction of neutrophilia and liver biochemistry. Six weeks after the commencement of treatment, both ESR and CRP had normalised and the patient was weaned off prednisolone.

\section{Discussion}

Acute rheumatic fever is an inflammatory disorder that can occur 2-4 weeks after a group A streptococcus (GAS) infection such as tonsillopharyngitis. It is most common in children and is typically a disease of poverty and low socioeconomic class. ${ }^{1}$ ARF has an incidence of less than 2 cases/100,000 population/year in developed countries compared to 250 cases/100,000 population/ year in the indigenous Australasian population. ${ }^{2}$ Some patients have a genetic predisposition to the disease, with a positive family history increasing the risk of developing the condition. ${ }^{1}$

Antigens from particular strains of GAS share similarities with self-antigens, which have been obtained through molecular autoantibody mimicry and immune complex formation, and T cell infiltration ensues. ${ }^{1,3}$ This results in fever and inflammation of the joints, skin, heart and brain.

Migratory polyarthritis is usually the earliest manifestation, typically affecting large joints with an overlapping onset. Carditis can affect all three layers of the heart, although the endocardium of the mitral and aortic valves are most often affected. Valvulitis can result in regurgitation and subsequent heart failure. Carditis can be subclinical and identified on echocardiography. Sydenham chorea involves abrupt, non-rhythmic involuntary muscle movements and is a late manifestation. Erythema marginatum occurs in only $5 \%$ of patients; it is a fleeting erythematous nonpruritic rash affecting the limbs or trunk. Subcutaneous nodules are firm, painless lesions that develop over bony prominences and resolve within a few weeks. They are similar to rheumatoid nodules but smaller. Uncommon manifestations of ARF include abdominal and chest pain, liver derangement, malaise and anaemia. ${ }^{1,2,4}$

Diagnosis is based on fulfilling the 2015 Jones revised criteria (Table 1), which requires evidence of a recent GAS infection and the presence of either two major criteria or one major criteria and two minor criteria. ${ }^{4}$ The criteria are subdivided on the basis of population risk. The main differentials are post-streptococcal reactive arthritis, viral arthritis and chronic inflammatory arthritis. Clinical assessment and investigations can help to exclude these differentials. ${ }^{2}$

Acute treatment aims to eradicate GAS with antibiotics and to treat the manifestations. Arthritis is treated with corticosteroids or high-dose nonsteroidal anti-inflammatory drugs (NSAIDs) such as naproxen 500-1,250 mg daily or aspirin 80-100 mg/kg/ day. Carditis is treated with high-dose corticosteroids; if heart failure develops, this is treated with conventional medication.
Table 1. Revised 2015 Jones criteria for the diagnosis of acute rheumatic fever (ARF) based on population-risk

\begin{tabular}{|c|c|c|}
\hline \multirow{3}{*}{ Major criteria } & Low-risk populations & $\begin{array}{l}\text { Moderate / high-risk } \\
\text { populations }\end{array}$ \\
\hline & Migratory polyarthritis & $\begin{array}{l}\text { Migratory polyarthritis/ } \\
\text { monoarthritis }\end{array}$ \\
\hline & Carditis & Carditis \\
\hline \multirow{6}{*}{ Minor criteria } & Chorea & Chorea \\
\hline & Erythema marginatum & Erythema marginatum \\
\hline & Subcutaneous nodules & Subcutaneous nodules \\
\hline & Polyarthralgia & Monoarthralgia \\
\hline & Fever $\geq 38.5^{\circ} \mathrm{C}$ & Fever $\geq 38.0^{\circ} \mathrm{C}$ \\
\hline & $\begin{array}{l}\mathrm{ESR} \geq 60 \mathrm{~mm} / \mathrm{hour} \\
\text { and/or CRP } \geq 30 \mathrm{mg} / \mathrm{L}\end{array}$ & $\begin{array}{l}\mathrm{ESR} \geq 30 \mathrm{~mm} / \mathrm{hour} \\
\text { and/or CRP } \geq 30 \mathrm{mg} / \mathrm{L}\end{array}$ \\
\hline \multirow{4}{*}{$\begin{array}{l}\text { Evidence of } \\
\text { GAS infection }\end{array}$} & $\begin{array}{l}\text { Prolonged PR interval } \\
\text { on ECG }\end{array}$ & $\begin{array}{l}\text { Prolonged PR interval } \\
\text { on ECG }\end{array}$ \\
\hline & \multicolumn{2}{|c|}{ Positive throat culture } \\
\hline & \multicolumn{2}{|c|}{ Elevated/rising ASO titre } \\
\hline & \multicolumn{2}{|c|}{ Positive rapid streptococcal antigen test } \\
\hline \multicolumn{3}{|c|}{$\begin{array}{l}\text { Low-risk population is defined as an ARF incidence } \leq 2 \text { per } 100,000 \text { school-aged } \\
\text { children or } \leq 1 \text { per } 1000 \text { population per year. For a diagnosis, two major criteria } \\
\text { or one major and two minor criteria must be fulfilled in the presence of a } \\
\text { recent group A streptococcus (GAS) infection. }{ }^{4}\end{array}$} \\
\hline \multicolumn{3}{|c|}{$\begin{array}{l}\mathrm{ASO}=\text { antistreptolysin } \mathrm{O} ; \mathrm{CRP}=\mathrm{C} \text {-reactive peptide; } \mathrm{ECG}=\text { electrocardiogram; } \\
\mathrm{ESR}=\text { erythrocyte sedimentation rate }\end{array}$} \\
\hline
\end{tabular}

Surgery may be necessary if valvular regurgitation develops. Chorea is generally treated conservatively though antiepileptics or corticosteroids can be given if this manifestation is severe. ${ }^{2,3}$

Monthly prophylactic benzathine penicillin is recommended to reduce the risk of rheumatic heart disease development; it has better efficacy and compliance compared with daily oral alternatives such as phenoxymethylpenicillin. It is given for 5-10 years depending on the presence of carditis. ${ }^{5}$

\section{Learning points}

> Consider ARF in any patient presenting with joint symptoms following an upper respiratory tract infection

$>$ ASO titres can help to identify recent GAS infection

> Carditis must always be excluded by ECG and echocardiography

> Management includes eradication of GAS and the use of antiinflammatories

> Use of long-term prophylactic antibiotics is imperative in preventing rheumatic heart disease.

\section{Consent for publication}

Written consent was obtained from the patient to publish the clinical details in this article.

\section{References}

1 Webb RH, Grant C, Harnden A. Acute rheumatic fever. BMJ 2015;351:3443 
2 RHD Australia (ARF/RHD writing group), National Heart Foundation of Australia and the Cardiac Society of Australia and New Zealand. The Australian guideline for prevention, diagnosis and management of acute rheumatic fever and rheumatic heart disease, 2nd edn. 2012.

3 World Health Organization. Rheumatic fever and rheumatic heart disease: report of a WHO expert consultation. Geneva: WHO, 2001.

4 Gewitz MH, Baltimore RS, Tani LY et al. Revision of the Jones Criteria for the diagnosis of acute rheumatic fever in the era of Doppler echocardiography: a scientific statement from the American Heart Association. Circulation 2015;131:1806.
5 Gerber MA, Baltimore RS, Eaton CB et al. Prevention of rheumatic fever and diagnosis and treatment of acute streptococcal pharyngitis. A Scientific Statement From the American Heart Association Rheumatic Fever, Endocarditis, and Kawasaki Disease Committee of the Council on Cardiovascular Disease in the Young, the Interdisciplinary Council on Functional Genomics and Translational Biology, and the Interdisciplinary Council on Quality of Care and Outcomes Research. Circulation 2009:119:1541-51.

Address for correspondence: Dr Asim Khan, Mile End Hospital, Barts Health NHS Foundation Trust, London E1 4DG, UK. Email: Asim.khan5@bartshealth.nhs.uk
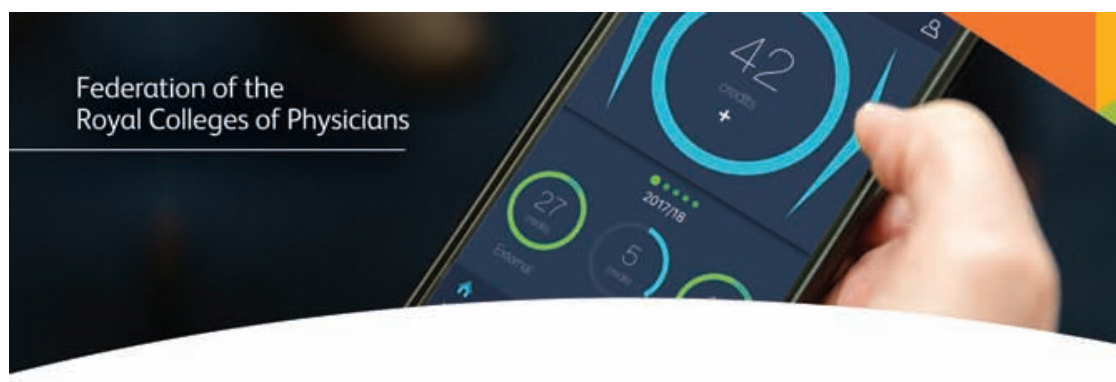

\section{Download the new Physicians' CPD app} Record and reflect on the go

> Add and reflect on your educational activities, wherever you are your changes will sync automatically with your online CPD diary"

$>$ Voice transcribe your development needs and reflections instantly

$>$ Access our list of over 5,000 approved activities

$>$ Keep track of your CPD and monitor your progress

to achieving your annual credit requirements

'An excellent and user-friendly app. I shall be using my CPD diary more frequently now!'

-Dr Andrew Lansdown, Consultant Endocrinologist

Simply download the Physicians' CPD app on your smartphone or tablet today and log in using your CPD diary account details. Now avaliable on the iOS App Store and the Google Play Store
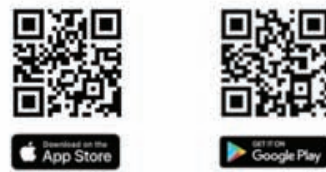

Physicians' CPD 